\title{
Difference and characteristics of anthocyanin from Cabernet Sauvignon and Merlot cultivated at five regions in Xinjiang
}

\author{
Ke ZHANG ${ }^{1 \#}\left(\mathbb{D}\right.$, Zhen-Zhen ZHANG ${ }^{1 \# \star}$, Lin YUAN ${ }^{2,3}$, Xiao-Tong GAO ${ }^{4,5}$, Qian LI $^{1}$
}

\begin{abstract}
Anthocyanin plays an important role in wine color and quality. The anthocyanin concentration in grapes depends on the variety and is influenced by environmental factors, such as temperature, sunlight, soil, and grapevine practice. In this study, the anthocyanin profiles of two varieties, namely Cabernet Sauvignon and Merlot, from five regions (11 plots) in Xinjiang were examined. The climatic parameters performed noticeable difference between northern and southern of Xinjiang region. Result showed that northern of Xinjiang possessed the relatively lower humidity and higher average temperature in comparison with southern area. In addition, the total anthocyanin profiles of Cabernet sauvignon, which in Changji, Wushitala, Heshuo respectively, were higher than of other plots. This result might be caused by which those have relatively higher altitude than in other plots. For merlot, the higher anthocyanin concentrations performed in southern of Xinjiang, which could be contributed to the lower average temperature and higher relative humidity. Comparing Cabernet sauvignon and Merlot, the latter was easily affected by environment factors, and the anthocyanin composition and concentration of Merlot showed significant differences in different regions.
\end{abstract}

Keywords: anthocyanin; grape; xinjiang; region; HPLC-MS.

Practical Application: The article was comprehensive clarified anthocyanin composition and compounds of Cabernet sauvignon and Merlot from different regions in Xinjiang. It can be useful to differentiate the feature and find the relationship of different regions. We can provide more valuable information for cultivating and wine-making to Xinjiang region.

\section{Introduction}

Anthocyanins are flavonoids with a cationic flavylium structure and appear in different colors depending on their particular chemical structure and the $\mathrm{pH}$ of the solutions in which they are present (Castañeda-Ovando et al., 2009). Anthocyanins play an important role in the color of grapes and wine and in particular can contribute to the organoleptic properties, such as color and taste (Esteban et al., 2001; Gómez-Míguez et al., 2006; González-Manzano et al., 2009). After veraison, anthocyanins accumulation are the main material in change of color during the grape berry development. And in wine making, anthocyanins are degraded and transform into stable polymerization (GarcíaPuente Rivas et al., 2006).

The quality of grape is a key factor affecting the quality of wine. As is known to all, the concentration and relative abundance of individual and total anthocyanins vary among red grape due to genetic control and development regulation. Genetic factors mostly determine anthocyanin biosynthesis. However, anthocyanin synthesis is affected by many factors, such as climate, soil status, altitude, and viticulture practice (Song et al., 2015; Xing et al., 2015). Mira de Orduña (2010) proved that climate and microclimate are key factors determining grape quality. The exposure of grape bunches to light increases the accumulation of anthocyanins, whereas darkness can severely reduce anthocyanin accumulation (Downey et al., 2007; Mira de Orduña, 2010). Highly night temperature prevents anthocyanin synthesis in Tokay grapes. And high night temperature $\left(>25^{\circ} \mathrm{C}\right)$ remarkably decreases the coloration of Cabernet sauvignon grapes in comparison with fruits ripened at nighttime temperatures between $15^{\circ} \mathrm{C}$ and $20^{\circ} \mathrm{C}$ (Kliewer \& Torres, 1972).

The Xinjiang Uygur Autonomous Regions (referred to as Xinjiang) is located in northwest China with a latitude of $34-49^{\circ}$, and its total surface area is 1.66 million $\mathrm{km}^{2}$. The Xinjiang region is characterized by a high day-to-night temperature difference with long sunshine duration and high sunshine intensity. Its major soil type is made up of sandy and/or rocky soils. Compared with grapes cultivated in the Xinjang region, those cultivated in the northern and southern areas of Tianshan Mountain, which have different weather conditions and performances, including growing degree days and phenolic content.

The varieties of Cabernet sauvignon and Merlot are widely cultivated worldwide, similar to those in Xinjiang. Liang et al. (2014) reported that the characteristics of the anthocyanin compounds from grapes of Cabernet sauvignon and Merlot in five wine regions in China. The anthocyanins of grapes 
from Cabernet sauvignon and Merlot planted in the Shacheng area of china have also been characterized (Shi et al., 2016). However, few studies have explored two red grape varieties in the entire Xinjiang area. The present study aimed to compare the anthocyanins of Cabernet sauvignon and Merlot harvested from five small wine-making regions. The findings are expected to help enhance the quality of the grape berries via appropriate cultivation techniques, and aid the evaluation of the wine-making potential of grape cultivars.

\section{Materials and methods}

\subsection{Chemicals and standards}

Standard malvidin-3-O-glucoside chloride was obtained from Sigma-Aldrich Co. (St. Louis, MI, USA). Methanol, formic acid, and acetonitrile (HPLC grade) were purchased from the Fisher Company (Fairlawn, NJ, USA). Deionized water $(<18 \mathrm{M} \Omega$ resistance) was obtained from a Milli-Q Element water purification system (Millipore, Bedford, MA, USA).

\subsection{Grape samples}

Grapes of Cabernet sauvignon and Merlot were collected at the stage of commercial harvest from different grapevines in 2018. Grape berries were collected from bunches in the middle zone of the spurs. The berries were randomly selected from the upper and lower areas until 300 berries were collected. The samples were taken back to the laboratory and stored at $-40{ }^{\circ} \mathrm{C}$ until use. The berry skins were peeled and frozen in liquid nitrogen, vacuum freeze-dried, and stored in refrigerated bags. The samples obtained from different wine-making areas are shown in Table 1. Given the different climates in each grape wine region, the quality of the grapes harvested depended on the date of harvest in previous years. Table 2 presents the total soluble solids (TSS), total acid content, and $\mathrm{pH}$ of grape berries from 11 grapevines. The berries were manually crushed order to remove the seeds and then squeezed. The juice was collected in a container. The chemical characteristics of the grapes, including total soluble solids, total acid and $\mathrm{pH}$, were tested. Total acid content was determined following the national standard (GB/T 15037-2006) method using $\mathrm{NaOH}$ solution

Table 1. Region soil types and grape cultivars from different regions in 2018.

\begin{tabular}{|c|c|c|c|c|}
\hline \multicolumn{2}{|c|}{ Grape grown region } & \multirow{2}{*}{$\begin{array}{c}\text { Geographic information } \\
44^{\circ} 32^{\prime} \mathrm{N} 86^{\circ} 20^{\prime} \mathrm{E}, 471.4 \mathrm{~m}\end{array}$} & \multirow{2}{*}{$\begin{array}{c}\text { Region soil type } \\
\text { Sandy soil }\end{array}$} & \multirow{2}{*}{$\begin{array}{c}\text { Cultivars } \\
\text { Cabernet Sauvignon Merlot }\end{array}$} \\
\hline Hami & Hami (HM) & & & \\
\hline Turpan & Shanshan (SS) & $42^{\circ} 85^{\prime} \mathrm{N} 90^{\circ} 23^{\prime} \mathrm{E}, 431.4 \mathrm{~m}$ & Sandy soil & Cabernet Sauvignon Merlot \\
\hline \multirow[t]{2}{*}{ Tianshan-mountain of north } & Changji (CJ) & $43^{\circ} 78^{\prime} \mathrm{N} 87^{\circ} 65^{\prime} \mathrm{E}, 935.2 \mathrm{~m}$ & Sandy soil & Cabernet Sauvignon Merlot \\
\hline & Shihezi (SHZ) & $44^{\circ} 32^{\prime} \mathrm{N} 86^{\circ} 05^{\prime} \mathrm{E}, 442.9 \mathrm{~m}$ & Sandy soil & Cabernet Sauvignon Merlot \\
\hline Yili valley & 70 group $(70)$ & $43^{\circ} 95^{\prime} \mathrm{N} 81^{\circ} 33^{\prime} \mathrm{E}, 662.5 \mathrm{~m}$ & Sandy soil & Cabernet Sauvignon Merlot \\
\hline \multirow[t]{3}{*}{ Yanqi-Heshuo } & Yanqi (YQ) & $42^{\circ} 05^{\prime} \mathrm{N} 86^{\circ} 34^{\prime}$ E, $1055.3 \mathrm{~m}$ & Heavy soil & Cabernet Sauvignon Merlot \\
\hline & Quhui country $(\mathrm{QH})$ & $42^{\circ} 26^{\prime} \mathrm{N} 87^{\circ} 16^{\prime} \mathrm{E}, 1067.3 \mathrm{~m}$ & Medium soil & Cabernet Sauvignon Merlot \\
\hline & Wushitala country (WSTL) & $42^{\circ} 25^{\prime} \mathrm{N} 86^{\circ} 80^{\prime} \mathrm{E}, 1085.4 \mathrm{~m}$ & Sandy soil & Cabernet Sauvignon Merlot \\
\hline
\end{tabular}

Table 2. Chemical characteristics of grape berries from different regions.

\begin{tabular}{|c|c|c|c|c|c|c|c|c|c|c|c|}
\hline \multirow{3}{*}{ 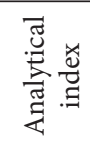 } & \multirow{3}{*}{ Hami } & \multicolumn{10}{|c|}{ CS } \\
\hline & & \multirow{2}{*}{$\begin{array}{c}\text { Turpan } \\
\text { Shanshan }\end{array}$} & \multicolumn{3}{|c|}{ TSMN } & \multicolumn{3}{|c|}{$\mathrm{YH}$} & \multirow{2}{*}{$\frac{\text { Yili valley }}{70 \text { group }}$} & \multirow[b]{2}{*}{62 group } & \multirow[b]{2}{*}{67 group } \\
\hline & & & Changji & Wujiaqu & Shihezi & Yanqi & Quhui & Wushitala & & & \\
\hline $\begin{array}{l}\text { Total } \\
\text { acidity } \\
\text { (g/L) }\end{array}$ & $9.17 \pm 0.16 \mathrm{a}$ & $5.76 \pm 0.09 f$ & $6.70 \pm 0.04 \mathrm{e}$ & $4.99 \pm 0.24 h$ & $6.64 \pm 0.09 e$ & $6.98 \pm 0.09 \mathrm{~d}$ & $5.46 \pm 0.17 \mathrm{~g}$ & $8.59 \pm 0.08 b$ & $7.15 \pm 0.09 \mathrm{~d}$ & $6.98 \pm 0.07 \mathrm{~d}$ & $8.31 \pm 0.15 c$ \\
\hline \multirow[t]{4}{*}{$\mathrm{pH}$} & $3.53 \pm 0.04 \mathrm{f}$ & $3.38 \pm 0.01 \mathrm{a}$ & $3.76 \pm 0.01 \mathrm{c}$ & $3.75 \pm 0.01 \mathrm{c}$ & $3.69 \pm 0.01 \mathrm{~d}$ & $3.70 \pm 0.02 \mathrm{~d}$ & $3.81 \pm 0.15 b$ & $3.44 \pm 0.01 \mathrm{~h}$ & $3.64 \pm 0.02 \mathrm{e}$ & $3.52 \pm 0.04 \mathrm{~g}$ & $3.64 \pm 0.01 \mathrm{e}$ \\
\hline & \multicolumn{9}{|c|}{ ML } & & \\
\hline & \multirow[t]{2}{*}{ Hami } & Turpan & \multicolumn{3}{|c|}{ TSMN } & \multicolumn{3}{|c|}{$\mathrm{YH}$} & Yili valley & & \\
\hline & & Shanshan & Changji & Wujiaqu & Shihezi & Yanqi & Quhui & Wushitala & 70 group & & \\
\hline $\begin{array}{l}\text { TSS } \\
\left({ }^{\circ} \text { Brix }\right)\end{array}$ & $24.37 \pm 0.05 f$ & $27.10 \pm 0.01 \mathrm{a}$ & $26.73 \pm 0.05 b$ & $24.30 \pm 0.08 \mathrm{f}$ & $25.13 \pm 0.05 d$ & $25.67 \pm 0.09 c$ & $23.80 \pm 0.08 \mathrm{~g}$ & $23.17 \pm 0.05 h$ & $24.80 \pm 0.04 \mathrm{e}$ & & \\
\hline $\mathrm{pH}$ & $3.85 \pm 0.01 b$ & $3.97 \pm 0.02 \mathrm{a}$ & $3.75 \pm 0.01 d$ & $3.60 \pm 0.03 \mathrm{f}$ & $3.76 \pm 0.01 \mathrm{~d}$ & $3.60 \pm 0.01 \mathrm{ef}$ & $3.62 \pm 0.03 \mathrm{e}$ & $3.56 \pm 0.01 \mathrm{~g}$ & $3.81 \pm 0.02 c$ & & \\
\hline
\end{tabular}

CS: Cabernet Sauvignon; ML: Merlot; TSMN: Tianshan-mountain of north; YH: Yanqi; TSS: Total soluble solids. Data are mean \pm standard deviation of triplicate tests. Different letters in each row represent significant difference at a significant level of 0.05 . 


\subsection{Extraction of anthocyanins}

The freeze-dried skin samples were ground into powder by using a grinding machine which was A 11 basic Analytical mill. One tenth of dry powder was extracted with $1 \mathrm{~mL}$ of $50 \%$ methanol aqueous solution (methanol/water, 1:1, v/v). The extract was ultrasonicated for 20 min keeping in dark place and lower than $25^{\circ} \mathrm{C}$. The extracted solvent and grape skin were separated by centrifugation at $12,000 \mathrm{rpm}$ for $15 \mathrm{~min}$ at $4{ }^{\circ} \mathrm{C}$. The supernatant was poured out and stored at $-40^{\circ} \mathrm{C}$. Each samples was analyzed twice. Anthocyanin extraction was performed as previously described (Downey et al., 2007).

\subsection{Analysis of anthocyanins}

Grape berry anthocyanins were detected by high-performance liquid chromatography-electronic spray ionization-tandem mass spectrometry (HPLC-ESI-MS/MS). Anthocyanins were analyzed on the basis of previous work (He et al., 2010). An Agilent 1100 series LC-MSD trap VL instrument with a diode array detector(DAD) and a reversed-phase column was used (Kromasil C18, $250 \mathrm{~mm}$ $\times 4.6 \mathrm{~mm}, 5 \mu \mathrm{m}$ ). An elution gradient was accompanied by two solvents: solvent A: water-formic acid-acetonitrile (92:2:6), solvent B: water-formic acid-acetonitrile (44:2:54). The gradient program was as follows: $6 \%$ to $10 \%$ for $4 \mathrm{~min}, 10 \%$ to $25 \%$ for $8 \mathrm{~min}$, isocratic $25 \% \mathrm{~B}$ for $1 \mathrm{~min}$, and then $25 \%$ to $40 \%$ for $7 \mathrm{~min}, 40 \%$ to $60 \%$ for $15 \mathrm{~min}$, then $60 \%$ to $100 \%$ for $5 \mathrm{~min}$, and finally $100 \%$ to $6 \%$ for $5 \mathrm{~min}$. The column was held at $50{ }^{\circ} \mathrm{C}$ and was flushed at a flow rate of $1.0 \mathrm{~mL} / \mathrm{min}$. The detection wavelength was $525 \mathrm{~nm}$, and the injection volumes were $30 \mu \mathrm{L}$. Mass spectrometry was performed using ESI, positive ion mode, $100-1500 \mathrm{mz}-\mathrm{l}$ sub-scan range, 30 psi nebulizer pressure, $10 \mathrm{~L} / \mathrm{min}$ dryer flow rate, and $325^{\circ} \mathrm{C}$ drying gas temperature. Individual anthocyanins were identified by elution order and retention times with commercial standards. The anthocyanins detected were quantified by an external standard method with malvidin-3-O-glucoside. Anthocyanin content was expressed in $\mathrm{mg} / \mathrm{g}$ dry grape skin and converted to percentages.

\subsection{Statistical analysis}

Mean, standard deviation, and standard curve were calculated using Microsoft Excel 2013 software. One-way ANOVA analysis was performed using SPSS 22.0. Heat map analysis was performed on MetaboAnalyst 4.0 (MetaboAnalyst, 2018) with auto-scaling normalization by using the detected anthocyanins as variables to determine the similarity of the wine-making grape cultivars.

\section{Results}

\subsection{Climatic parameters analysis of five regions}

In this work, the samples were selected from five regions with similar cultivation methods. The relative anthocyanin content of the grapes cultivated in wine-making regions with different climates were determined. Considering that more the samples were collected from selected locations than from others, we chose the typical climate data in each production area. Climate data were obtained from the China Meteorological Data Sharing Service System. Figure 1 shows the climate data, including rainfall, sunshine, average temperature, day of maximum and minimum temperature, and average relative humidity, generated from five regions.

The data illustrated remarkable differences among the five regions. During rainfall, Hami, Tianshan Mountain of North and Yili Valley experienced higher than Turpan and Yanqi-Heshuo. The average temperature in the five regions showed some differences. The average temperature of Turpan region, ranging from $13.9^{\circ} \mathrm{C}$ to $37.3^{\circ} \mathrm{C}$, was higher than that in other regions. By contrast, its average relative humidity between $18 \%$ and $57 \%$ was lower than that in other regions. The average temperature in four regions, namely, Hami, Tianshan Mountain of North, Yili Valley and Yanqi-Heshuo, gradually decreased between $10^{\circ} \mathrm{C}$ to $32.3^{\circ} \mathrm{C}$, between $11.4^{\circ} \mathrm{C}$ to $32.4^{\circ} \mathrm{C}$, between $7.2^{\circ} \mathrm{C}$ to $30.6^{\circ} \mathrm{C}$, and between $10.4{ }^{\circ} \mathrm{C}$ to $28.4^{\circ} \mathrm{C}$, respectively. The opposite was observed in their average relative humidity levels. The daily max temperature in Hami and Turpan regions was markedly higher than in others region, whereas the minimum temperature of Hami was lower than that in Tianshan Mountain in the north. In the five regions, sunshine hour showed no evident diversity.

\subsection{Heat map analysis}

Among the grape anthocyanins detected from Cabernet sauvignon and Merlot from five regions, 14 anthocyanins were identified and considered for composition and profiling. Table 3 shows the anthocyanins of the grape skins extracted chromatogram information which included five primary anthocyanidins, acetylated anthocyanindin, and coumarylated anthocyanidin. For the grape samples detected, all primarily anthocyanins and acetylated anthocyanin were identified in Cabernet sauvignon and Merlot from five regions. Cy-ac was not detected in Cabernet sauvignon from shihezi, and Dp-coum was only found in Cabernet sauvignon from Changji and Merlot from Changji and Quhui. Samples from all regions were detected with Pet-coum anthocyanin, but it was not found in group 70 .

In Cabernet sauvignon, a high profile of malvidin anthocyanins were found with their acetyl and coumaryl. Delphinidin and petunidin anthocyanin content were abundant in Merlot (Dimitrovska et al., 2011; González-Neves et al., 2007; Liang et al., 2014).

Heat map statistical analysis showed the anthocyanin relative concentrations from five regions. As shown in Figure 2, with the orange color representing a high level, the anthocyanin concentrations of Cabernet sauvignon in Changji, group 67, and Wushitala were at a relatively high level, particularly in terms of $\mathrm{Cy}, \mathrm{Dp}$, and Pet with corresponding acylation. In the same figure, with the blue color representing a low level, the Shanshan, group 62, and Yanqi samples showed a relatively low anthocyanin profile. Anthocyanins of Mal and Mal-ac levels were high in the Shanshan and group 70 samples. The Malcoum level was higher in the Wujiaqu and Shihezi samples than in other vine samples. For Merlot, the Peo and Cy with acylate derivative and coumarylate derivative were low in Wujiaqu and group 70 samples. The levels of Dp and Pet with their acylates were relatively low in the Shanshan samples. 
Table 3. Anthocyanin compounds identified by LC-DAD and LC-ESI/MS in the grape skin extracts of Cabernet sauvignon and Merlot.

\begin{tabular}{cccccc}
\hline No. & RT (min) & Precursor m/z & Fragments m/z & Compound & Abbreviation \\
\hline 1 & 4.57 & 465 & 303 & Delphinidin-3-O-glucoside & Dp \\
2 & 6.27 & 449 & 287 & Cyanidin-3-O-glucoside & Cy \\
3 & 7.21 & 479 & 317 & Petunidin-3-O-glucoside & Pt \\
4 & 9.69 & 463 & 301 & Peonidin-3-O-glucoside & Pn \\
5 & 10.63 & 493 & 331 & Malvidin-3-O-glucoside & Mv \\
6 & 12.43 & 507 & 303 & Delphinidin-3-O-(6-O-acetyl)-glucoside & Dp-acet \\
7 & 15.93 & 491 & 287 & Cyanidin-3-O-(6-O-acetyl)-glucoside & Cy-acet \\
8 & 17.30 & 521 & 317 & Petunidin-3-O-(6-O-acetyl)-glucoside & Pt-acet \\
9 & 19.58 & 611 & 303 & Peonidin-3-O-(6-O-acetyl)-glucoside & Dp-coum \\
10 & 21.19 & 505 & 301 & Malvidin-3-O-(6-O-acetyl)-glucoside & Pn-acet \\
11 & 22.10 & 535 & 331 & Petunidin-3-O-(6-O-coumaryl)-glucoside & Pt-coum \\
12 & 26.69 & 625 & 317 & Peonidin-3-O-(6-O-coumaryl)-glucoside & Pn-coum \\
13 & 28.03 & 609 & 301 & Malvidin-3-O-(6-O-coumaryl)-glucoside & Mv-coum \\
14 & 30.31 & 639 & 331 & &
\end{tabular}

RT: Retention time; m/z: mass-to-charge ratio.
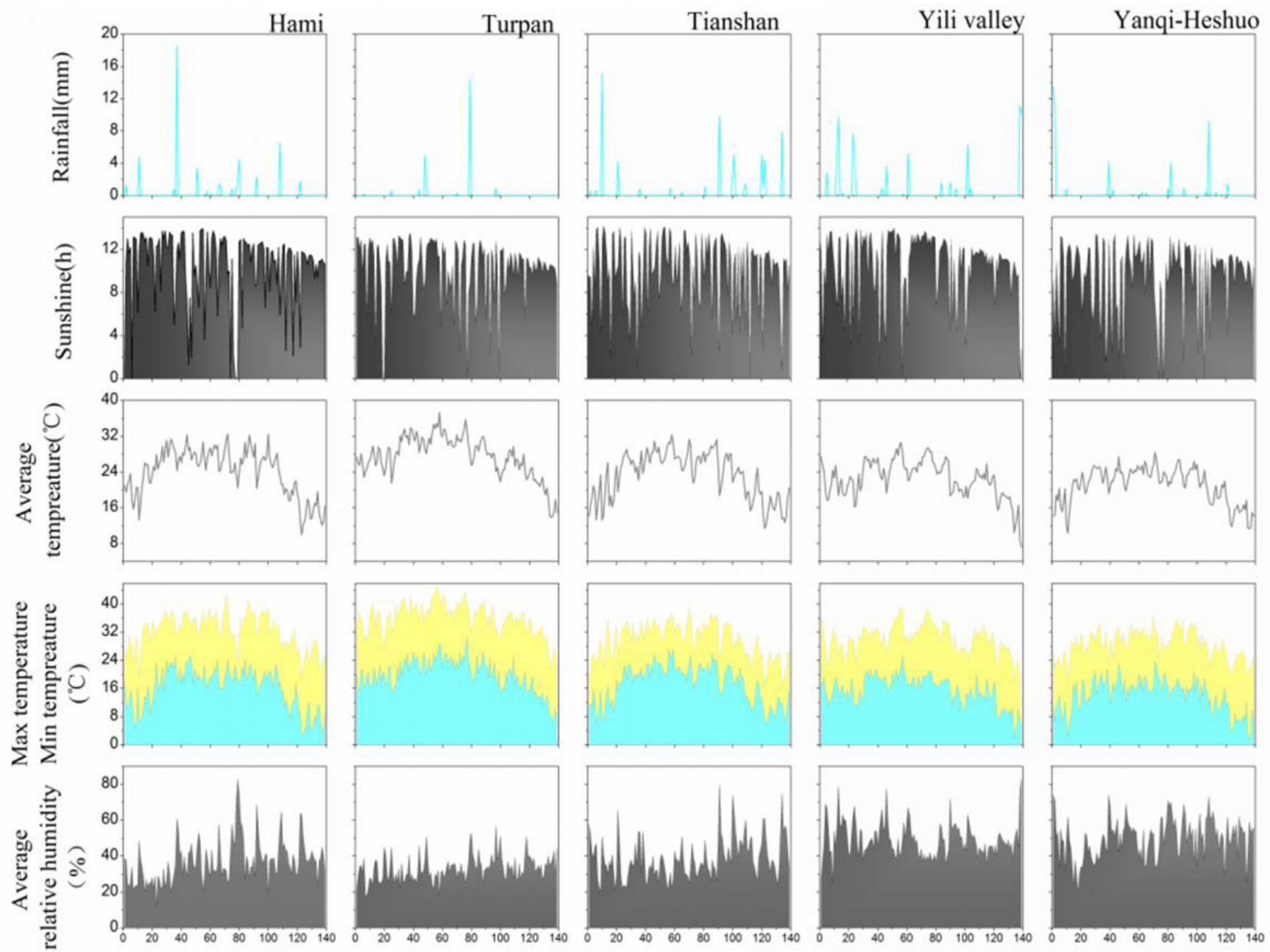

Figure 1. Climate parameters in five locations sampled during grape ripening from full bloom to harvest in 2018.

\subsection{Comparison of anthocyanins of from different grapevines}

The total anthocyanin content is shown in Figure 3. The total anthocyanin content of Cabernet sauvignon in Turpan and Northern of Tianshan Mountain was higher than that of Merlot.
The opposite trend was observed for Hami, Yili Valley and Yanqi-Heshuo. The total anthocyanins of the two varieties from Turpan grapevines were lower than those from other regions. In summary, the total anthocyanin content of Cabernet sauvignon did not remarkably differ, except for the Changji, Wushitala and 
Shanshan samples. By contrast, the conditions of Merlot from five regions showed remarkable diversity.

The anthocyanins were divided into different groups on the basis of the anthocyanin metabolic pathway. As shown in figure 4, the di-hydroxylated anthocyanins of Cabernet sauvignon in all grape collected plots in Changji, Wushitala and Quhui were $>1 \mathrm{mg} / \mathrm{g}$, whereas those in other plots were $<1 \mathrm{mg} / \mathrm{g}$. The dihydroxylated anthocyanin concentrations of Merlot in Hami, Changji, Yanqi and Quhui ranged from $1.79 \mathrm{mg} / \mathrm{g}$ to $2.11 \mathrm{mg} / \mathrm{g}$ and were higher than those in other samples collected. The trihydroxylated anthocyanins of Cabernet sauvignon in all plots had few remarkable difference, except for those in the Shanshan, which were $<7 \mathrm{mg} / \mathrm{g}$. The tri-hydroxylated anthocyanins of Merlot in the Heshuo samples were higher than those in the samples from other regions and those in the Shanshan samples were the lowest. Cabernet sauvignon in northern of Tianshan Mountain showed higher acylated anthocyanin content in comparison with that in other regions. The samples from Yili Valley and Yanqi-Heshuo region presented similar contents. The situation of Merlot was different from that of Cabernet sauvignon. The two plots in Yanqi-Heshuo region had abundant tri-hydroxylated anthocyanins. Yili Valley, Hami and Northern
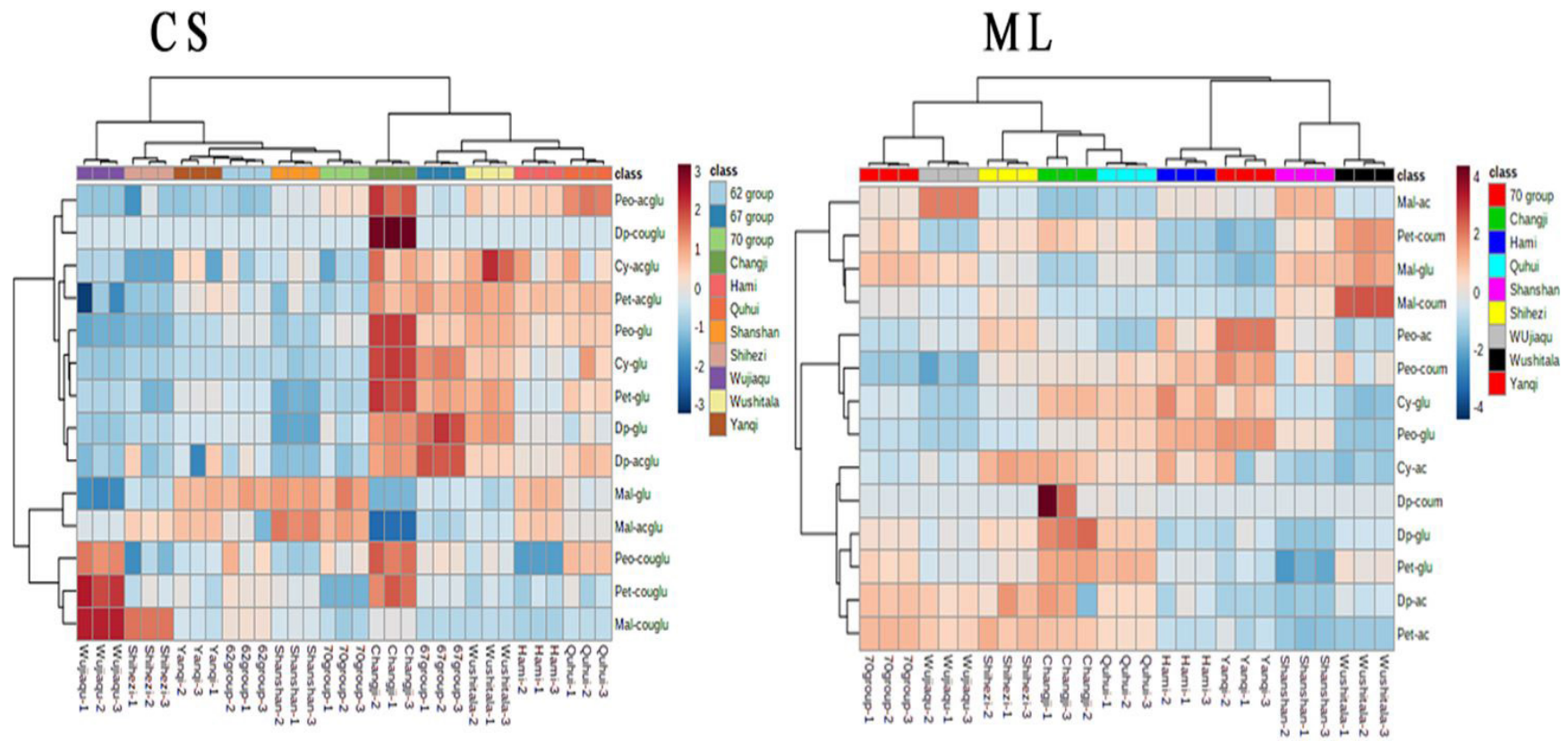

Figure 2. Heat map representation of anthocyanins from two grape cultivars from five regions sampled in 2018. The orange and blue colors indicate high and low levels, respectively. The greater the orange intensity, the higher the level; the greater the blue intensity, the lower the level. The right column contains all anthocyanins detected in the grapes (refer to Table 3 for abbreviations).
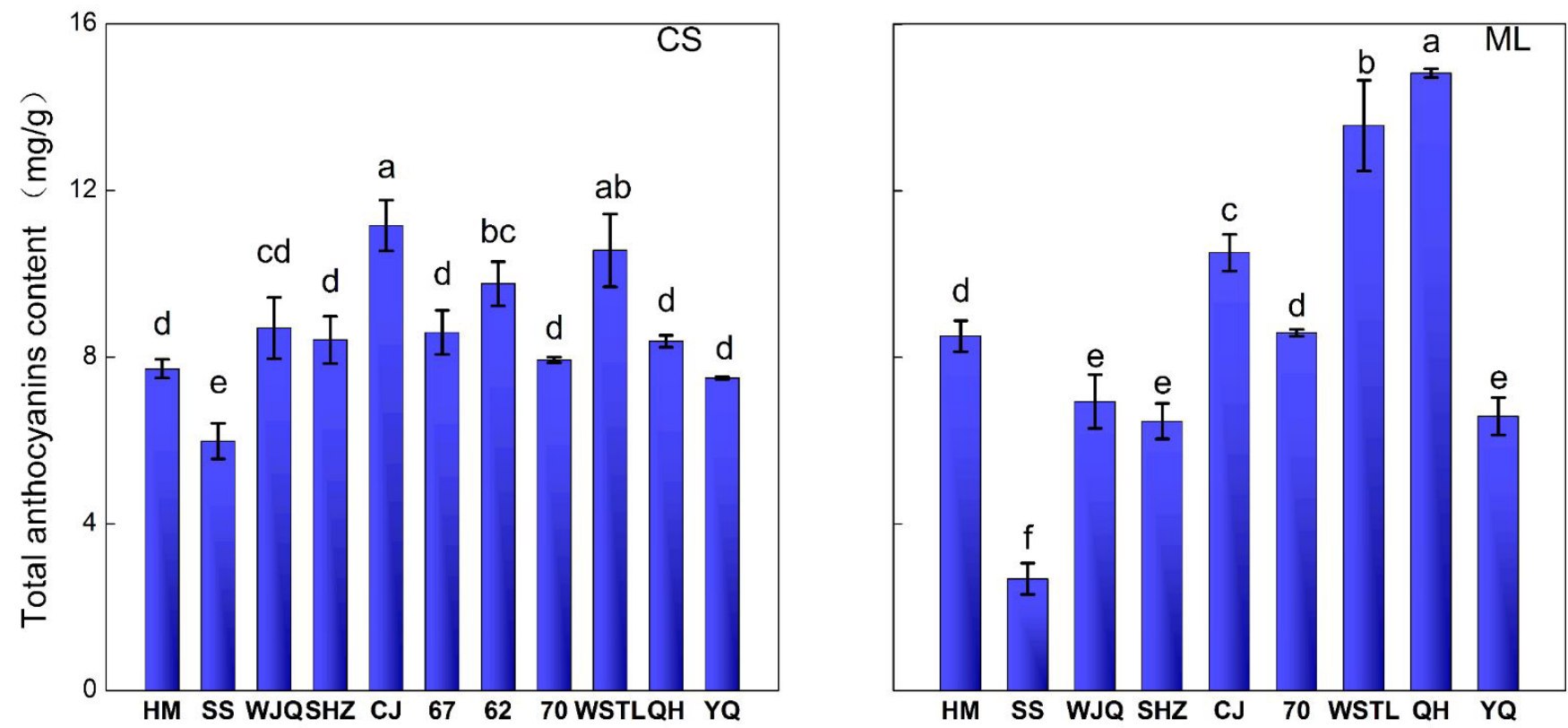

Figure 3. Total anthocyanin contents of two red grapes from eleven plots in five regions (refer to Table 1 for abbreviations). 


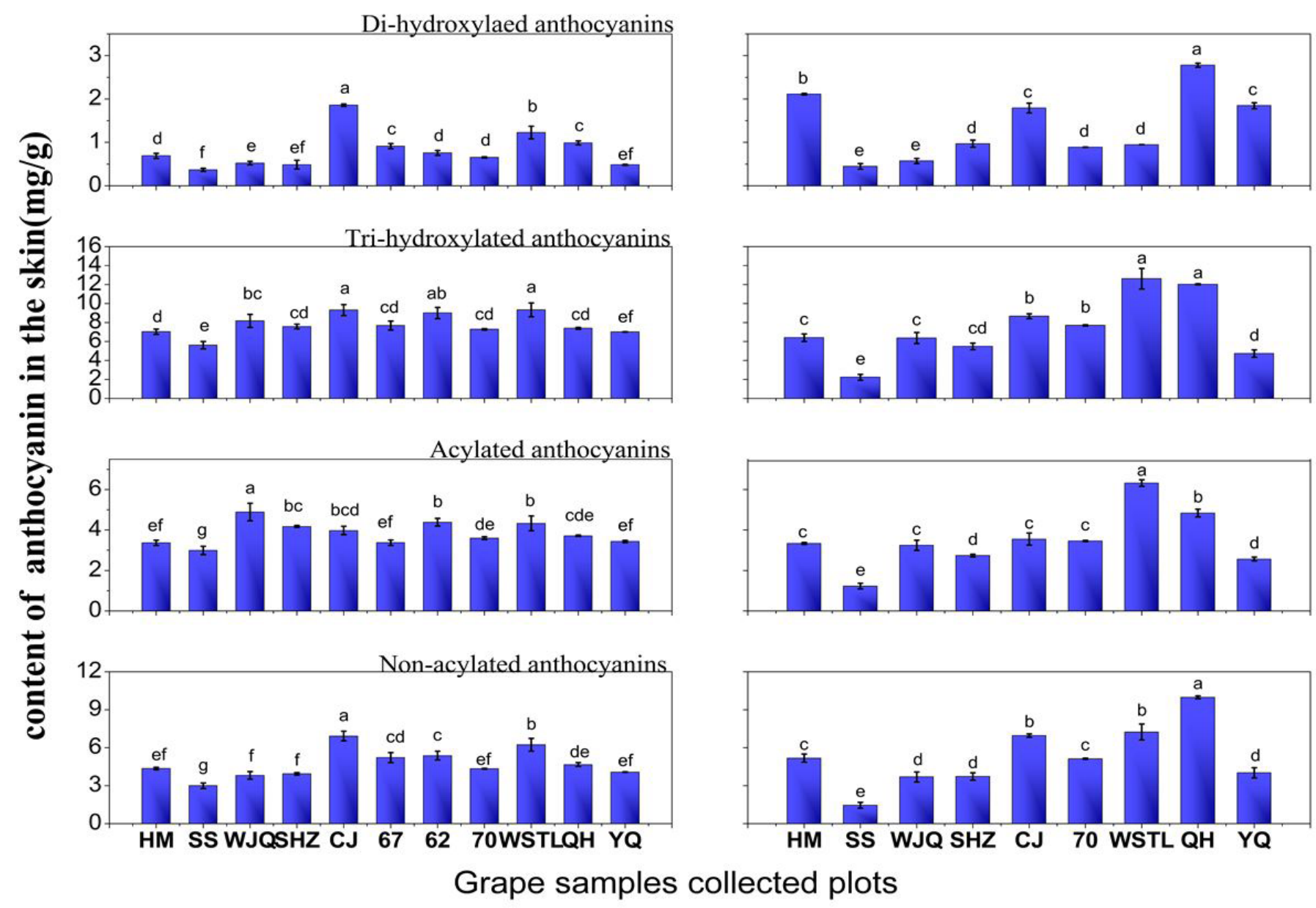

Figure 4. Distribution of anthocyanin content from different biosynthetic branch pathways and the acylation and non-acylation of berry skins of two cultivars.

of Tianshan Mountain showed no remarkale differences in tri-hydroxylated content. The non-acylated anthocyanins of Cabernet sauvignon and Merlot in Changji, Yili and Heshuo were higher than those in other plots.

All identified compounds were grouped on the basis of anthocyanin distribution (cyanidins, delphinidins, peonidins, petunidins and malvidins). The resulting classification of the anthocyanin profiles of grape varieties is presented in Table 4 . The grape varieties differed in anthocyanin distribution. The highest proportion of malvidins was found in Cabernet and Merlot from all plots. A characteristic anthocyanin pattern was found in Merlot, which showed more abundant cyanidins and petunidins than Cabernet sauvignon. The delphinidins contents of Cabernet sauvignon and Merlot in Northern Tianshan Mountain and Yili Valley were similar. Figure 5 shows the proportion of anthocyanins in different groups. The results suggested that the samples from Yili Valley and Yanqi-Heshuo had low acylation. By contrast, the Hami and Turpan samples showed high non-acyated anthocyanin concentration. This result was consistent with those of previous studies that reported on cool climate possibly being conductive to increased non-acylation (Liang et al., 2014). The ratios of di/tri anthocyanins of Cabernet sauvignon and Merlot differed. The di-anthocyanins concentrations of Cabernet sauvignon in
Yili and Heshuo presented an increase, and the tri-anthocyanin proportions in Hami and Turpan were high. Meanwhile, Merlot in Hami and Yanqi had the highest proportion of di-anthocyanins, particularly peonidin anthocyanin derivatives. In the comparison of Cabernet sauvignon and Merlot, the tri-anthocyanins in the Changji and 70 group samples were similar and mainly included a proportion of delphinidin derivatives.

\section{Discussion}

The anthocyanin synthesis of grape is mainly affected by genetic, which the anthocyanin composition of grapes was initially determined by genetic factors. The several researchers have reported that anthocyanin compounds of variable varieties were dominant depended on genetic levels, but the actually levels of same variety is performed difference when they grown in different regions (Pomar et al., 2005; Revilla et al., 2001).

However, climate characteristics, such as light intensity and temperature, strongly influence berry composition (Arozarena et al., 2002). Cabernet sauvignon in the Hami and Turpan regions showed lower anthocyanin content than the samples from other regions. Merlot in Heshuo had high anthocyanin content. This result indicated reduced anthocyanin synthesis accumulation under high temperature conditions 
Table 4. Anthocyanin profiles of Cabernet sauvignon and Merlot from five regions. The data cover 11 sampling plots of Cabernet sauvignon and 9 sampling plots of Merlot.

\begin{tabular}{|c|c|c|c|c|c|c|c|c|c|c|c|}
\hline $\begin{array}{c}\text { Anthocyanins } \\
(\%)\end{array}$ & Hami & Shanshan & Wujiaqu & Shihezi & Changji & 67 group & 62 group & 70 group & Wushitala & Quhui & Yanqi \\
\hline \multirow{2}{*}{ Cyanindins } & $1.26 \pm 0.47 \mathrm{~cd}$ & $0.61 \pm 0.01 \mathrm{ef}$ & $.40 \pm 0.01 \mathrm{ef}$ & $0.22 \pm 0.01 \mathrm{f}$ & $2.47 \pm 0.21 \mathrm{a}$ & $1.98 \pm$ & $0.65=$ & $0.54 \pm 0.06 \mathrm{ef}$ & $1.94 \pm 0.33 b$ & $1.42 \pm 0.25 c$ & $0.90 \pm 0.02 \mathrm{de}$ \\
\hline & $3.45 \pm 0.81 \mathrm{a}$ & $1.26 \pm 0.01 \mathrm{de}$ & $0.83 \pm 0.34 \mathrm{e}$ & $2.40 \pm 0.16 c$ & $3.32 \pm 0.06 \mathrm{ab}$ & & & $1.67 \pm 0.13 \mathrm{~d}$ & $0.62 \pm 0.06 \mathrm{e}$ & $2.94 \pm 0.01 \mathrm{abc}$ & $2.67 \pm 0.18 b c$ \\
\hline \multirow{2}{*}{ Delphinidins } & $7.71 \pm 0.54 \mathrm{de}$ & $5.53 \pm 0.22 \mathrm{f}$ & $5.60 \pm 0.24 f$ & $4.04 \pm 1.36 \mathrm{~g}$ & $14.19 \pm 0.45 a$ & $8.66 \pm 0.04 \mathrm{~cd}$ & $7.14 \pm 0.71 \mathrm{e}$ & $7.83 \pm 0.05 \mathrm{de}$ & $9.66 \pm 0.09 b c$ & $10.33 \pm 0.20 b$ & $5.81 \pm 0.28 \mathrm{f}$ \\
\hline & $2.57 \pm 1.15 \mathrm{~d}$ & $1.91 \pm 0.06 \mathrm{~d}$ & $5.17 \pm 0.52 c$ & $7.51 \pm 0.20 b$ & $13.01 \pm 0.11 \mathrm{a}$ & & & $7.00 \pm 0.13 b$ & $3.70 \pm 0.06 \mathrm{~cd}$ & $8.24 \pm 0.01 b$ & $3.08 \pm 1.91 \mathrm{~d}$ \\
\hline \multirow{2}{*}{ Peonidins } & $4.77 \pm 0.01 \mathrm{c}$ & $1.04 \pm 0.10 \mathrm{f}$ & $2.16 \pm 0.11 \mathrm{ef}$ & $2.98 \pm 0.28 \mathrm{de}$ & $10.51 \pm 0.42 \mathrm{a}$ & $10.06 \pm 0.70 \mathrm{a}$ & $4.06 \pm 0.41 \mathrm{~cd}$ & $3.57 \pm 1.20 \mathrm{~cd}$ & $7.51 \pm 0.23 b$ & $4.92 \pm 1.10 c$ & $4.26 \pm 0.44 c d$ \\
\hline & $21.41 \pm 0.49 \mathrm{~b}$ & $15.16 \pm 0.21 \mathrm{c}$ & $7.10 \pm 0.16 \mathrm{~g}$ & $12.60 \pm 0.13 \mathrm{e}$ & $13.73 \pm 0.30 \mathrm{~d}$ & & & $8.68 \pm 0.04 f$ & $6.38 \pm 0.49 \mathrm{~g}$ & $15.82 \pm 0.18 \mathrm{c}$ & $25.42 \pm 0.73 a$ \\
\hline \multirow{2}{*}{ Petunidins } & $5.54 \pm 0.29 \mathrm{~d}$ & $3.36 \pm 0.49 f$ & $4.69 \pm 0.54 \mathrm{e}$ & $3.30 \pm 0.11 f$ & $10.38 \pm 0.39 \mathrm{a}$ & $7.91 \pm 0.11 b$ & $5.31 \pm 0.30 \mathrm{de}$ & $3.91 \pm 0.11 \mathrm{f}$ & $7.86 \pm 0.43 b$ & $6.85 \pm 0.47 c$ & $5.62 \pm 0.05 d$ \\
\hline & $6.77 \pm 0.13 e$ & $3.51 \pm 0.70 \mathrm{~g}$ & $7.56 \pm 0.11 \mathrm{~d}$ & $8.95 \pm 0.32 c$ & $11.58 \pm 0.06 a$ & & & $10.05 \pm 0.09 b$ & $8.14 \pm 0.29 \mathrm{~d}$ & $10.64 \pm 0.22 b$ & $5.94 \pm 0.40 \mathrm{f}$ \\
\hline \multirow{2}{*}{ Malvidins } & $80.71 \pm 0.71 d$ & $89.46 \pm 0.81 \mathrm{a}$ & $87.15 \pm 0.63 b$ & $89.46 \pm 1.19 a$ & $62.91 \pm 0.63 \mathrm{~g}$ & $71.41 \pm 0.83 \mathrm{f}$ & $82.85 \pm 0.88 c$ & $84.16 \pm 1.20 c$ & $73.04 \pm 1.09 f$ & $76.49 \pm 1.08 \mathrm{e}$ & $83.43 \pm 0.75 c$ \\
\hline & $65.82 \pm 0.71 \mathrm{e}$ & $78.18 \pm 0.84 b$ & $79.35 \pm 0.13 b$ & $68.55 \pm 0.81 \mathrm{~d}$ & $58.37 \pm 0.30 \mathrm{~g}$ & & & $72.61 \pm 0.18 c$ & $81.18 \pm 0.91 \mathrm{a}$ & $62.37 \pm 0.42 \mathrm{f}$ & $62.90 \pm 1.40 \mathrm{f}$ \\
\hline
\end{tabular}

Data are mean \pm standard deviation of triplicate tests. Different letters in each row represent significant difference at a significant level of 0.05 .
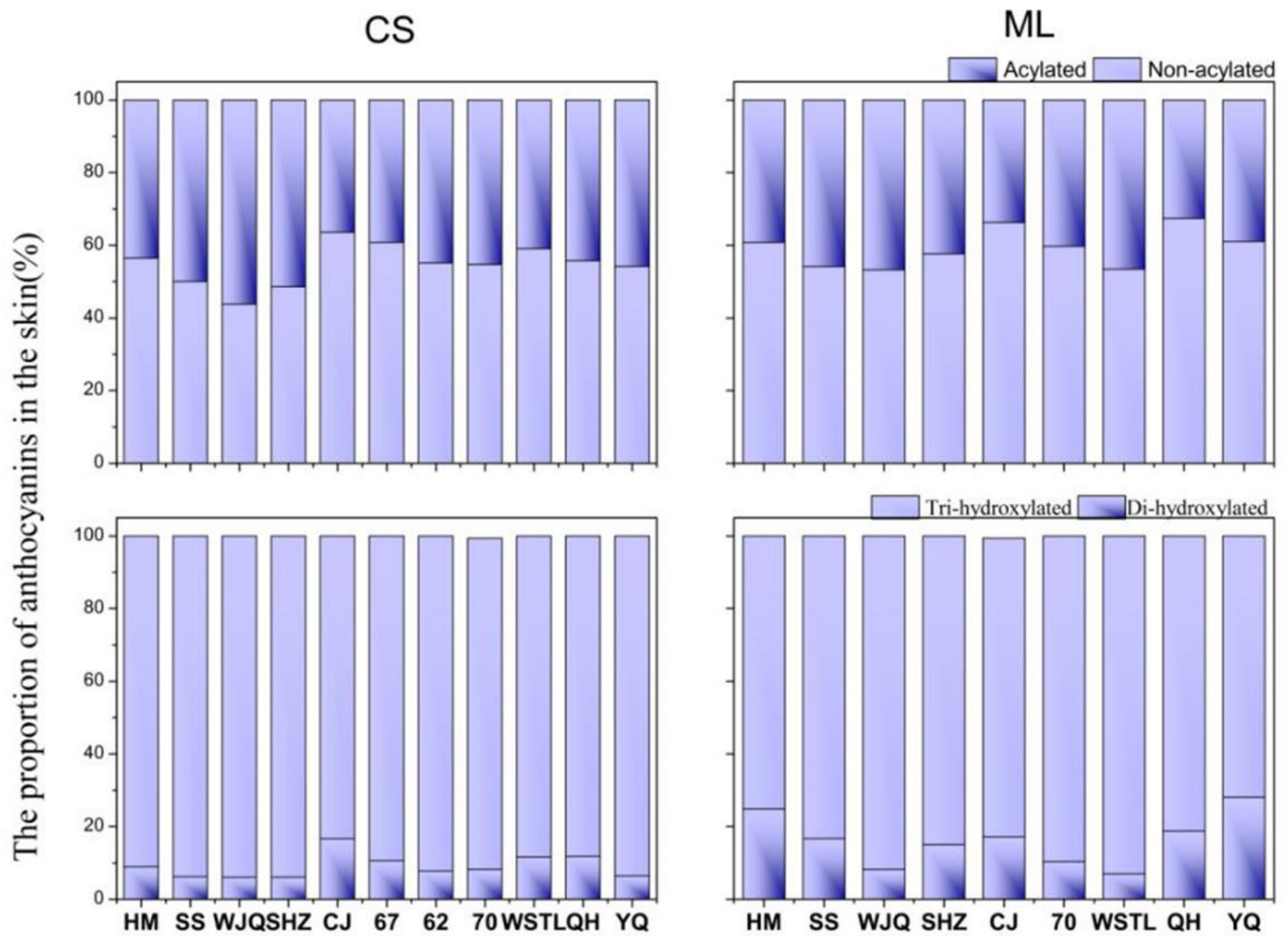

Grape samples collected location

Figure 5. Proportion of acylated and non-acylated anthocyanins and two biosynthetic branch pathways.

(Martinez de Toda \& Balda, 2015; Van Leeuwen et al., 2004). The effects of sunlight exposure on berry composition of two red grapes in the Central San Joaquin Valley of California have been investigated. Grape skin anthocyanins increased linearly with increasing sunlight exposure (Bergqvist et al., 2001). Five regions in Xinjiang were compared in the current work, and the results showed that Northern of Tianshan Mountain had more sunshine hours than other regions, but the plots here did not present the highest anthocyanin content. The previously studied influence of sunlight on anthocyanins agrees well with our results (Bergqvist et al., 2001). Downey et al. (2007) applied opaque boxes to bunches of Shiraz grapes prior to flowering at reduced sunlight. However, the boxes were designed to maintain significant while excluding light and thus to minimize changes 
in temperature and humidity. These results clarified that shaded does not remarkably change the anthocyanin content of grape and alter their anthocyanin composition. By contrast, Spayd et al. (2002) separated the effects of sunlight and temperature on the anthocyanins of Merlot berry skins and found that decreased total anthocyanin concentrations were cause by temperature and not to sunlight exposure. No significant differences are found in the anthocyanin contents of Cabernet sauvignon and Merlot (Dimitrovska et al., 2011; Jensen et al., 2008). In addition, the anthocyanin content of Cabernet sauvignon is higher than that of Merlot (Shi et al., 2016). The total anthocyanin contents of Merlot in Turpan and Northern of Tianshan Mountain was lower than that of Cabernet sauvignon in both regions. The two plots in Heshuo presented a high total anthocyanin content. Our studies indicated that Merlot is easily affected by altitude conditions.

Shi et al. (2016) found high levels of delphinidins and cyanidins in Merlot. Dimitrovska et al. (2011) found that the Merlot contained abundant amounts of delphinidin and petunidin anthocyanins. The present study found that Merlot has ample cyanidins and peonidins. This results is inconsistent with those of previous studies. We also found that delphinidins in the Northern of Tianshan Mountain and Yili Valley samples were similar. For acylation anthocyanins, Liang et al. (2014) reported that acylation easily accumulates with high temperature and humidity. Our studies suggested that the ratio of acylation to total anthocyanin content in the Hami, Turpan and Northern of Tianshan Mountain samples was higher than that in the Yili valley and Yanqi-Heshuo samples. By contrast, the non-acylation in Cabernet sauvignon in the Yili Valley and Yanqi-Heshuo samples was high. Clearly, the proportions of di-hydroxylated and tri-hydroxylated anthocyanins did not evidently differ in Cabernet sauvignon. This results is inconsistent with that of previous studies showing that the di/tri ratio increases with high light and temperature (Gao-Takai et al., 2019). The present study found that the di/tri proportion of anthocyanins not only affects on climate, but is also dependent on vineyard location.

In summary, the concentrations of anthocyanin compounds from five regions mainly depended on variety and were affected by climate condition. The data of climatic showed significant difference with northern and southern of Tianshan mountain. Comparing anthocyanin content in northern and southern of Tianshan mountain, this results suggested that the grapes cultivated at southern of Tianshan mountain were rich in anthocyanin profiles.

\section{Conclusion}

To our knowledge, the present work indicated that had more differences in climate from different regions of Xinjiang, especially temperature and precipitation, which led to have some diversities in anthocyanin characteristic. The highest average temperature and lowest rainfall significantly influenced anthocyanin accumulation, which contributed to the lowest anthocyanin profiles in Turpan than in other region. The relatively higher temperature in Turpan and northern of Tianshan mountain induced more acylated anthocyanins. Changji area and Heshuo area showed abundant anthocyanin concentrations in two varieties. In addition, comparing Cabernet sauvignon and
Merlot in all regions, we demonstrated that Merlot has higher di-hydroxylated anthocyanin than Cabernet sauvignon and was easily affected by environment factors, and the difference in regions showed more significant.

\section{Acknowledgements}

This study was financially supported by the National Nature Science Foundation of China (31660547) and the Shanxi Province Research Transformation Funding (201604D132034). Authors sincerely thanked Dr. Chang-qing Duan and his team for helping us on the analysis of anthocyanins applied for HPLC-MS.

\section{References}

Arozarena, I., Ayestarán, B., Cantalejo, M., Navarro, M., Vera, M., Abril, I., \& Casp, A. (2002). Anthocyanin composition of Tempranillo, Garnacha and Cabernet Sauvignon grapes from high- and low-quality vineyards over two years. European Food Research and Technology, 214(4), 303-309. http://dx.doi.org/10.1007/s00217-001-0471-0.

Bergqvist, J., Dokoozlian, N., \& Ebisuda, N. (2001). Sunlight exposure and temperature effects on berry growth and composition of Cabernet Sauvignon and Grenache in the Central San Joaquin Valley of California. American Journal of Enology and Viticulture, 52(1), 1-7.

Castañeda-Ovando, A., Pacheco-Hernández, M. L., Páez-Hernández, M. E., Rodríguez, J. A., \& Galán-Vidal, C. A. (2009). Chemical studies of anthocyanins: a review. Food Chemistry, 113(4), 859-871. http:// dx.doi.org/10.1016/j.foodchem.2008.09.001.

Dimitrovska, M., Bocevska, M., Dimitrovski, D., \& Murkovic, M. (2011). Anthocyanin composition of Vranec, Cabernet Sauvignon, Merlot and Pinot Noir grapes as indicator of their varietal differentiation. European Food Research and Technology, 232(4), 591-600. http:// dx.doi.org/10.1007/s00217-011-1425-9.

Downey, M. O., Mazza, M., \& Krstic, M. P. (2007). Development of a stable extract for anthocyanins and flavonols from grape skin. American Journal of Enology and Viticulture, 58(3), 358-364.

Esteban, M. A., Villanueva, M. J., \& Lissarrague, J. R. (2001). Effect of irrigation on changes in the anthocyanin composition of the skin of $\mathrm{cv}$ Tempranillo (Vitis vinifera $\mathrm{L}$ ) grape berries during ripening. Journal of the Science of Food and Agriculture, 81(4), 409-420. http://dx.doi. org/10.1002/1097-0010(200103)81:4<409::AID-JSFA830>3.0.CO;2-H.

Gao-Takai, M., Katayama-Ikegami, A., Matsuda, K., Shindo, H., Uemae, S., \& Oyaizu, M. (2019). A low temperature promotes anthocyanin biosynthesis but does not accelerate endogenous abscisic acid accumulation in red-skinned grapes. Plant Science, 283, 165-176. http://dx.doi.org/10.1016/j.plantsci.2019.01.015. PMid:31128686.

García-Puente Rivas, E., Alcalde-Eon, C., Santos-Buelga, C., RivasGonzalo, J. C., \& Escribano-Bailón, M. T. (2006). Behaviour and characterisation of the colour during red wine making and maturation. Analytica Chimica Acta, 563(1-2), 215-222. http:// dx.doi.org/10.1016/j.aca.2005.11.044.

Gómez-Míguez, M., González-Manzano, S., Escribano-Bailón, M. T., Heredia, F. J., \& Santos-Buelga, C. (2006). Influence of different phenolic copigments on the color of malvidin 3-glucoside. Journal of Agricultural and Food Chemistry, 54(15), 5422-5429. http://dx.doi. org/10.1021/jf0604586. PMid:16848527.

González-Manzano, S., Duenas, M., Rivasgonzalo, J., Escribanobailon, M., \& Santosbuelga, C. (2009). Studies on the copigmentation between anthocyanins and flavan-3-ols and their influence in the colour expression of red wine. Food Chemistry, 114(2), 649-656. http://dx.doi.org/10.1016/j.foodchem.2008.10.002. 
González-Neves, G., Franco, J., Barreiro, L., Gil, G., Moutounet, M., \& Carbonneau, A. (2007). Varietal differentiation of Tannat, Cabernet-Sauvignon and Merlot grapes and wines according to their anthocyanic composition. European Food Research and Technology, 225(1), 111-117. http://dx.doi.org/10.1007/s00217-006-0388-8.

He, J.-J., Liu, Y.-X., Pan, Q.-H., Cui, X.-Y., \& Duan, C.-Q. (2010). Different anthocyanin profiles of the skin and the pulp of Yan73 (Muscat Hamburg $\times$ Alicante Bouschet) grape berries. Molecules, 15(3), 1141-1153. http://dx.doi.org/10.3390/molecules15031141. PMid:20335969.

Jensen, J. S., Demiray, S., Egebo, M., \& Meyer, A. S. (2008). Prediction of wine color attributes from the phenolic profiles of red grapes (Vitis vinifera). Journal of Agricultural and Food Chemistry, 56(3), 1105-1115. http://dx.doi.org/10.1021/jf072541e. PMid:18173238.

Kliewer, W. M., \& Torres, R. E. (1972). Effect of controlled day and night temperatures on grape coloration. American Journal of Enology and Viticulture, 23(2), 71-77.

Liang, N.-N., Zhu, B.-Q., Han, S., Wang, J.-H., Pan, Q.-H., Reeves, M. J., Duan, C. Q., \& He, F. (2014). Regional characteristics of anthocyanin and flavonol compounds from grapes of four Vitis vinifera varieties in five wine regions of China. Food Research International, 64, 264-274. http://dx.doi.org/10.1016/j.foodres.2014.06.048. PMid:30011650.

Martinez de Toda, F., \& Balda, P. (2015). Quantifying the effect of temperature on decoupling anthocyanins and sugars of the grape (Vitis vinifera L.'Maturana Tinta de Navarrete'). Vitis: Journal of Grapevine Research, 54(3), 117-120.

MetaboAnalyst. (2018). MetaboAnalyst 4.0. Retrieved from http:// www.metaboanalyst.ca/

Mira de Orduña, R. (2010). Climate change associated effects on grape and wine quality and production. Food Research International, 43(7), 1844-1855. http://dx.doi.org/10.1016/j.foodres.2010.05.001.
Pomar, F., Novo, M., \& Masa, A. (2005). Varietal differences among the anthocyanin profile of 50 red table grape cultivars studied by high performance liquid chromatography. Journal of Chromatography $A$, 1094(1-2), 34-41. http://dx.doi.org/10.1016/j.chroma.2005.07.096. PMid:16257286.

Revilla, E., García-Beneytez, E., Cabello, F., Martín-Ortega, G., \& Ryan, J.-M. (2001). Value of high-performance liquid chromatographic analysis of anthocyanins in the differentiation of red grape cultivars and red wines made from them. Journal of Chromatography. A, 915(1), 53-60. http://dx.doi.org/10.1016/S0021-9673(01)00635-5. PMid:11358262.

Shi, P., Yue, T., Ai, L., Cheng, Y., Meng, J., Li, M., \& Zhang, Z. (2016). Phenolic compound profiles in grape skins of Cabernet Sauvignon, Merlot, Syrah and Marselan cultivated in the Shacheng area (China). South African Journal of Enology and Viticulture, 37(2), 132-138. http://dx.doi.org/10.21548/37-2-898.

Song, J., Smart, R., Wang, H., Dambergs, B., Sparrow, A., \& Qian, M. C. (2015). Effect of grape bunch sunlight exposure and UV radiation on phenolics and volatile composition of Vitis vinifera. Food Chemistry, 173, 424-431. http://dx.doi.org/10.1016/j.foodchem.2014.09.150. PMid:25466041.

Spayd, S. E., Tarara, J. M., Mee, D. L., \& Ferguson, J. (2002). Separation of sunlight and temperature effects on the composition of Vitis vinifera cv. Merlot berries. American Journal of Enology and Viticulture, 53(3), 171-182.

Van Leeuwen, C., Friant, P., Chone, X., Tregoat, O., Koundouras, S., \& Dubourdieu, D. (2004). Influence of climate, soil, and cultivar on terroir. American Journal of Enology and Viticulture, 55(3), 207-217.

Xing, R.-R., He, F., Xiao, H.-L., Duan, C.-Q., \& Pan, Q.-H. (2015). Accumulation pattern of flavonoids in Cabernet Sauvignon grapes grown in a low-latitude and high-altitude region. South African Journal of Enology and Viticulture, 36(1), 32-43. 